\title{
Evaluation of endothelialization of left atrial appendage occluder by three-dimensional transesophageal echocardiography and its influence factors
}

\author{
Lihong Wang \\ Qindao University Medical College Affiliated Yantai Yuhuangding Hospital \\ Hongyue Mao \\ Qindao University Medical College Affiliated Yantai Yuhuangding Hospital \\ Lei Shi \\ Qindao University Medical College Affiliated Yantai Yuhuangding Hospital \\ Hongyan Li \\ Qindao University Medical College Affiliated Yantai Yuhuangding Hospital \\ Guifang Song ( $\square$ 2308404266@qq.com ) \\ Qindao University Medical College Affiliated Yantai Yuhuangding Hospital
}

\section{Research}

Keywords: nonvalvular atrial fibrillation, left atrial appendage closure, Watchman occluder, endothelialization

Posted Date: March 28th, 2020

DOI: https://doi.org/10.21203/rs.3.rs-19568/v1

License: (c) (i) This work is licensed under a Creative Commons Attribution 4.0 International License. Read Full License 


\section{Abstract}

Background This study evaluated surface endothelialization of Watchman occluder (Boston Scientific) through comparing relevant indicators before and left atrial appendage closure (LAAC) in 68 non-valvular atrial fibrillation (AF) patients.

Methods Patients were monitored preoperatively by transthoracic echocardiography (TTE), transesophageal two-dimensional and three-dimensional echocardiography (2D-TEE, 3D-TEE), intraoperatively by 3D-TEE and angiocardiography, and followed at 3 and 6 months after operation by TEE.

Result It showed that the inner diameters of LAA ostium measured by TEE at $0^{\circ}, 90^{\circ}$ and $135^{\circ}$ before operation were correlated with corresponding maximum diameters measured by angiocardiography. The depth of LAA ostium measured at $90^{\circ}$ was correlated with the maximum depth measured by angiocardiography. The left atrial diameter, left ventricular diameter and left ventricular free wall $E / E^{\prime}$ decreased postoperatively. Compared T-test showed that BNP level and persistent AF might be risk factors for spontaneous echo contrast (SEC) or thrombosis of LAA. Multiple linear regression identified persistent AF, preoperative LAA spontaneous echo contrast or recent thrombotic event, and history of embolism in other parts were the influence factors of occluder endothelialization.

Conclusion: BNP level and persistent AF may be risk factors of left atrial appendage thrombosis. Treatment of $\mathrm{AF}$ and thrombus in left atrial appendage or other parts are beneficial to the prognosis of LAAC patients.

\section{Background}

Atrial fibrillation (AF) is the most common type of arrhythmia in clinical practice. In Chinese population the prevalence of $A F$ is $0.42 \%$ in people aged between $35-59$ years old and $1.83 \%$ in people over 60 years old [1]. AF leads to changes in the hemodynamics of the heart cavity and increases the possibility of atrial thrombosis. A study showed that more than $90 \%$ of atrial thrombi caused by non-valvular atrial fibrillation (NVAF) originate from the left auricle [2]. NVAF is an independent risk factor for ischemic stroke. The risk of thrombotic events is $5 \%$ per year. The risk of stroke in AF patients is 4-5 times higher than that in non-AF patients [3], and the 5-year stroke rate of AF patients is $20 \%-25 \%$ [4]. At present, clinical prevention and treatment of NVAF patients with ischemic stroke still mainly rely on long term use of anticoagulants. However, the clinical application and efficacy of anticoagulants are limited by many factors such as dosage, patient compliance and adverse reactions. According to the literature, among the NVAF patients with $\mathrm{CHA}_{2} \mathrm{DS}_{2}$-VASc score $\geq 2$ in Chinese population, $36.5 \%$ of them receive anticoagulants [5], and $44.4 \%$ of the anticoagulant users withdraw their medication within one year[6]. Left atrial appendage closure (LAAC) is a surgical procedure that blocks the ostium of left atrial appendage (LAA) to prevent thrombosis and thrombus detachment, so as to reduce the risk of stroke. LAAC has been recommended by relevant international guidelines as a new technology to prevent 
ischemic stroke in NVAF patients [7, 8], and its long-term prognosis is relatively reliable [9-11]. Since the Watchman LAA occluder (Boston Scientific, USA) appeared on the market in China in 2014, LAAC has developed rapidly in China, and the application of real-time transesophageal three-dimensional echocardiography (RT-3D-TEE) in interventional cardiosurgery has gradually increased. It does not obstructs surgical field of vision and plays important roles in intraoperative monitoring and postoperative follow-up. The purpose of this study is to evaluate the degree of occluder endothelialization after LAAC by 3D-TEE and discuss its influence factors based on the follow-up information of LAAC patients.

\section{Materials And Methods}

\section{Patients}

This study enrolled 68 patients with the diagnosis of AF and were scheduled for LAAC using Watchman (Boston Scientific, USA) occluder in our hospital from January, 2017 to September, 2019, including 48 males and 20 females, aged $45-86$ years old (63.68 \pm 9.43 years). Among them, 54 patients $(79.41 \%)$ had persistent AF, 14 (20.59\%) had paroxysmal AF. Thirty-one (45.59\%) patients had spontaneous echo contrast (SEC) of LAA blood flow or previous thrombosis history, and were treated with anticoagulant until meeting the surgical criteria. The Inclusion criteria of the study were: (1) age $\geq 18$ years; (2) with NVAF, including persistent and paroxysmal types; (3) $\mathrm{CHA}_{2} \mathrm{DS}_{2}$-VASc score $\geq 1$; (4) unable to take anticoagulants orally for a long time or had high risk of bleeding with anticoagulants. The exclusion criteria were: (1) cardiac insufficiency (EF < 30\%); (2) preoperative TEE showed thrombosis or suspicious thrombosis in LAA (except for thrombus disappeared after treatment); (3) atrial septal disease (defect, aneurysm, space-occupying lesion, etc.); (4) complicated with severe hepato-renal insufficiency, coagulation dysfunction, arterial aneurysm, cardiac valvulopathy, pulmonary insufficiency, or severe lesions of other organs. The age, gender, $\mathrm{BNP}, \mathrm{CHA}_{2} \mathrm{DS}_{2}$-VASc score and history of the patients were collected. This study was approved by the Ethics Committee of Yantai Yuhuangding Hospital, and informed consent of all patients were obtained.

\section{Preoperative ultrasonography}

All patients were examined for LAA thrombus by transthoracic echocardiography (TTE) and TEE before operation using Philips EPIQ 7c Color Doppler Ultrasound Diagnostic System, with S5-1 transthoracic probe (frequency 1-5 MHz) and $X 7-2 t$ transesophageal 3D probe (frequency 2-7 MHz). The inner diameter and depth of the ostium of LAA were measured at $0^{\circ}, 45^{\circ}, 90^{\circ}$ and $135^{\circ}$. The inner diameter was defined as the distance between the ostium of the circumflex branch of the left coronary artery in LAA wall and about $2 \mathrm{~cm}$ below the extension ridge of the left superior pulmonary vein (LSPV). The depth was defined as the distance between the middle point of the radial line of the LAA ostium and the tip of LAA (Figure 1). The shape and lobulation of LAA were displayed in multi plane by 3D imaging technology. 
After achieved anesthetization of patient, atrial septal puncture was performed via the femoral vein, and the catheter was sent for LAA angiocardiography to measure the maximum diameter and maximum depth of LAA ostium using the Philips Allura Xper ED20 digital flat-panel X-ray system.

\section{Intraoperative ultrasonography}

Appropriate Watchman occluder (Boston Scientific, USA) was selected according to the maximum inner diameter of the LAA ostium measured by RT-3D-TEE. The 3D configuration, size, and lobulation of LAA and its spatial position relationship with LSPV and mitral valve were observed. The atrial septum was punctured under the guidance of RT-3D-TEE. The puncture site was selected according to the position of LAA, which is usually posterior inferior to the oval fossa. The occluder was released at the right angle and position guided by RT-3D-TEE and angiocardiography. RT-3D-TEE was used to observe the real-time location, configuration, and shoulder protrusion of the occluder, its spatial relationship with the cardiac valve and the LSPV ostium, as well as any residual flow and pericardial effusion (Figure 2).

Successful occlusion should meet the PASS criteria[12]: (1) Position: device was distal to or at ostium of LAA; (2) Anchor: fixation anchor engaged or device was stable as determined by a 'tug test'-retracting the deployment knob and letting go, to assess return to original position; (3) Size: device compressed 8\%-30\% of original size; (4) Seal: device covered well, and residual flow was $<3 \mathrm{~mm}$ as seen on TEE.

\section{Follow-ups}

Patients were followed at 3 months and 6 months after operation for ECG, TTE and TEE to observe symptom improvement, location of occluder, residual flow of atrial septum and any thrombosis on the surface of occluder. Thickness of the endothelium on the occluder surface was also measured (Figure 3).

\section{Statistical analysis}

SPSS 20.0 software was used for statistical analysis. Measurement data was described as mean \pm standard deviation ( $\pm \mathrm{s}$ ) and was compared by Mann-Whitney $\mathrm{U}$ test. $\mathrm{CHA}_{2} \mathrm{DS}_{2}-\mathrm{VASc}$ scores were described as median, upper and lower quartiles and were compared by Kruskal-Wallis One-way ANOVA. Correlation between data measured by TEE and by angiocardiography were analyzed by Pearson correlation analysis. Changes of cardiac function before, 3 months after and 6 months after surgery were compared by One-way ANOVA with Tukey's multiple comparison test. Categorical data was compared by Fisher's exact test. Multiple linear regression was used to analyze the influence factors of postoperative surface endothelialization of occluder. $P<0.05$ indicated statistical significance.

\section{Results}

\section{Operation outcomes}

LAAC for all $68 \mathrm{AF}$ patients were successful, in which 53 cases (77.9\%) were completely occluded. Sixtyfour patients (94.12\%) underwent AF radiofrequency ablation at the same time. Fifteen cases $(22.1 \%)$ 
had small amount of residual flow during the operation, with flow stream $<3 \mathrm{~mm}$. By 3 months after operation, 4 out of the 15 cases still had residual flow, and another 17 cases developed residual flow as well. Among the 68 patients, shoulder protrusion occurred in $26(38.2 \%)$ cases during operation and in 18 (26.5\%) cases by 3 months post operation (including 12 standing cases and 6 newly developed cases). Thrombus on the surface of occluder was observed in 4 (5.8\%) patients at 3 months follow-up, which still persisted in 2 patients by 6 months post operation. Pericardial effusion was found in 1 case $(1.5 \%)$ during the operation, which disappeared after 3 months. There were no serious complications such as device detachment during or after the operation.

\section{Correlation between TEE and angiocardiography measurements}

Preoperative horizontal 3D-TEE measurements of the LAA ostium were: $0^{\circ}$ inner diameter $19.1 \pm 3.7 \mathrm{~mm}$, depth $28.3 \pm 6.5 \mathrm{~mm} ; 45^{\circ}$ inner diameter $18.5 \pm 3.6 \mathrm{~mm}$, depth $28.6 \pm 5.9 \mathrm{~mm} ; 90^{\circ}$ inner diameter $19.2 \pm$ $2.8 \mathrm{~mm}$, depth $29.6 \pm 5.8 \mathrm{~mm} ; 135^{\circ}$ inner diameter $21.7 \pm 3.2 \mathrm{~mm}$, depth $28.3 \pm 6.1 \mathrm{~mm}$. The maximum diameter and depth of the LAA ostium measured by intraoperative angiocardiography were $24.6 \pm 3.2$ $\mathrm{mm}$ and $29.3 \pm 2.8 \mathrm{~mm}$ respectively. By Pearson correlation analysis, we found correlations between the inner diameter of LAA ostium measured at $0^{\circ}, 90^{\circ}$ and $135^{\circ}$ and the maximum diameter measured by angiography $(P<0.05,0.001,0.01)$, and between the depth measured at $90^{\circ}$ by TEE and the maximum depth measured by angiography $(P<0.001)$ (Figure 4$)$.

\section{Changes of cardiac function after $L A A C$}

Summarized in Table 1 was the comparison of cardiac function indicators before, 3 months, and 6 months after the operation. The left atrial diameter (LAD), left ventricular diameter (LVD) and E/E' (peak transmitral velocity-to-distance of left ventricular free wall mitral annulus movement ratio) significantly decreased with time $(P<0.05)$, and the differences were significant between any two groups $(P<0.05)$.

\section{Risk factors of LAA SEC or thrombosis}

Patients were divided into SEC/thrombosis group and non-SEC group. Patient's age, gender, smoking history, hypertension, stroke, type of $\mathrm{AF}, \mathrm{CHA}_{2} \mathrm{DS}_{2}$-VASc score, and BNP level were compared between the two groups. We found significant difference in BNP level and persistent AF, indicating that high BNP level and persistent AF might be risk factors for SEC or thrombosis of LAA (Table 2).

\section{Influence factors of endothelialization of occluder surface after $L A A C$}

We compared the thickness of endothelialization of occluder surface 3 months and 6 months after LAAC. Result showed increased thickness of endothelialization at 6 months $(1.33 \pm 0.23 \mathrm{~mm})$ than 3 months $(1.19 \pm 0.19 \mathrm{~mm})$, however with no statistical significance $(Z=-1.92, P=0.06)$. A number of variables were analyzed by multiple linear regression to identify the influence factors of post-LAAC endothelialization. As shown in Table 3, we found that persistent AF, preoperative SEC of LAA blood flow or recent thrombotic 
events, and history of embolism in other parts were the independent influence factors of endothelialization of occluder surface $(P<0.05)$.

\section{Discussion}

In AF patients, the left atrium loses normal systolic function and reshape of LAA occurred, which slows down blood flow, increases risks of thrombosis and stroke. According to the AHA/ACC/HRS guideline for the management of patients with $A F$, anticoagulants (class IA) are recommended for patients with $\mathrm{CHA}_{2} \mathrm{DS}_{2}$-VASc score $\geq 2$ to prevent thrombus [13], while the $2016 \mathrm{ESC}$ guideline recommends use of anticoagulants (class IA) for male with $\mathrm{CHA}_{2} \mathrm{DS}_{2}$-VASc score $\geq 2$ and for women with $\mathrm{CHA}_{2} \mathrm{DS}_{2}-\mathrm{VASc}$ score $\geq 3$ [7]. However, the clinical application and efficacy of anticoagulants are limited by many factors such as dosage, patient compliance, and adverse reactions. ESC guideline recommends LAAC (class IIB) for patients with contraindications to long-term anticoagulation treatment [7]. The 5-year PREVAL [9] and PROTECT AF study [10], which enrolled 1114 patients including 732 implanted with LAA occluder, reported that Watchman occluder provided similar protective efficacy against ischemic stroke with that of warfarin in AF patients (HR 1.71, $P=0.080)$. In addition, the occluder group had significantly reduced risks of hemorrhagic stroke (HR 0.20, $\mathrm{P}=0.002)$, heart related mortality $(H R 0.59, \mathrm{P}=0.027)$ and unexplained mortality (HR 0.73, P = 0.035) than warfarin group [11]. The long-term efficacy of other brands of occluder still required further study. In recent years, LAAC has been recommended as a new technology for treating thromboembolic events in $\mathrm{AF}$ patients by international guidelines $[7,8]$.

In this study, 15 out of $68 \mathrm{AF}$ patients treated with Watchman occluder had intraoperative residual flow of less than $3 \mathrm{~mm}$ and another 17 cases developed residual flow 3 months after the operation. All the 17 cases had received radiofrequency ablation before the implantation of occluder. Therefore, the development of residual flow was likely due the slight displacement of occluder caused by restored active systolic function of LAA after surgery, or due to subsiding of edema in the extension ridge of LSPV. Since the residual flows were all less than $3 \mathrm{~mm}$, no clinical interventions were needed and patients were further followed.

RT-3D-TEE was used for preoperative evaluation and intraoperative monitoring in this study. Several studies have found that the accuracy of 3D-TEE was higher than that of 2D-TEE in pre-LAAC evaluation $[14,15]$, and that 3D-TEE was highly correlated with measurements by intraoperative angiocardiography, therefore can be routinely used for intraoperative monitoring of LAAC [16]. In this study, we found correlation between the inner diameters of LAA ostium measured in $0^{\circ}, 90^{\circ}$ and $135^{\circ}$ section by preoperative TEE and the maximum diameter measured by angiocardiography $(P<0.05)$, and the TEE measurement in $135^{\circ}$ section was closest to the angiocardiography measurement. The depth measured by $T E E$ in $90^{\circ}$ section was correlated with the maximum depth measured by angiocardiography $(P<0.05)$.

In AF patients, the contractility of left atrium decreases. As it lasts, the electrical remodeling, tissue remodeling and ion channel remodeling of the left atrium become more serious, which leads to a series of electrophysiological dysfunction and attenuates the connection between atrial myocytes and the signal 
transduction between atrial cells $[17,18]$. It has been reported that the peak strain of each left atrium wall in AF patients was significantly lower than that in non-AF patients, and that the pressure and load of the left atrium did not improve significantly shortly after LAAC [19]. The reporter believed that although LAAC could be used as a preventive measure to reduce the risk of thromboembolism, it did not fundamentally change the heart rate of AF patients, therefore had no significant impact on the mechanical function of left atrium. In our study, 64 patients (94.12\%) underwent AF radiofrequency ablation at the same time. We found gradually reduced LAD, LVD and E/E' at 3 months and 6 months post operation, suggesting improved function of left atrium and left ventricle in AF patients after improving the AF rhythm. Six cases developed shoulder protrusion 3 months after operation, which was likely attributed to the improvement of systolic function of left atrium and LAA after restoring the sinus rhythm. As the shoulder protrusion did not exceed $1 / 3$ of the inner diameter of the occluder, no clinical intervention was applied.

Evaluating the process of endothelialization on the occluder surface after LAAC is important for the postoperative treatment of AF patients. Delayed endothelialization might be an influence factor of thrombosis after device implantation [20]. Therefore, anti-thrombotic therapy must be carried out before the complete endothelialization of the occluder surface to prevent device-related thrombus event. Previous studies on the endothelialization of LAA occluder were limited to animal experiments, while only a few human cases were analyzed. Massarenti et al. [21] reported that a patient with hereditary hemorrhagic telangiectasia (HHT) suffered stroke 10 months after the implantation of Watchman occluder, which showed no endothelialization of the occluder surface after removing the device. HHT is an autosomal dominant hereditary disease with an incidence rate of about $1 / 5000$. In HHT patients, selective expression of the genes encoding TGF- $\beta$ pathway proteins leads to vascular endothelialization dysfunction, disorders of vascular smooth muscle development, and endothelial remodeling, which caused incomplete endothelialization of the occluder surface. Animal studies have found that complete endothelialization of LAA occluder occurred about 3 months after operation [22], and complete endothelialization of both sides of the occlusion device for atrial septal defect occurred 3 months after operation as well [23]. Therefore, in this study, we selected the time point of 3 months after LAAC for measuring the thickness of the surface endothelialization of the occluder. We found no statistically significant difference between the thickness of surface endothelialization 3 months and 6 months after LAAC. It is considered that the short-term effect on the area of occluder surface endothelialization after LAAC is greater than on its thickness. Previous research has reported incomplete surface endothelialization of the Amplatzer Cardiac Plug (St. Jude Medical) in $61 \%$ of LAAC patients $10 \pm 6$ months after the operation [24]. Multiple linear regression analysis found that persistent AF, SEC or recent thrombotic event, and thrombosis in other parts were independent factors influencing the degree of occluder surface endothelialization. Granier et al. [24] defined incomplete endothelialization as residual permeability on cardiac computed tomography without peridevice leak on TEE at follow-up after implantation of Watchman device (Boston Scientific) or Amplatzer Cardiac Plug (St. Jude Medical), and found incomplete endothelialization might be related to diabetes, persistent AF and implantation of oversized occluder. This was consistent with our finding that persistent AF was an influencing factor of occluder surface endothelialization. AF increases thrombogenic tendency by fulfilling the Virchow's triad 
[25]: alterations in normal blood flow, endothelium dysfunction, and abnormal coagulationanticoagulation-fibrinolytic system. In addition, in patients with persistent AF, the level of endothelial factor such as vWF (produced by endothelial cells and induced secretion by inflammatory response, oxidative stress, activation of renin-angiotension system) was significantly higher than that in patients with paroxysmal AF [26]. Electrical cardioversion and radiofrequency ablation could restore sinus rhythm and at the same time change endothelial function. Prosperi-Porta et al. [27] reported a case of secondary multiple organ thrombosis after LAAC. Autopsy showed that the thrombi formed earlier than LAAC. This was consistent with our finding that abnormal coagulation-fibrinolysis function in AF patients, combined with the difference in the efficacy of oral anticoagulants, increased the risk of thrombosis, which might be a potential predictor for delayed endothelialization after LAAC. Besides, alteration of BNP level could affect SEC and thrombosis of LAA. Therefore, routine monitoring of BNP level before surgery and during the follow-ups could evaluate the left atrial blood flow status, and predict the long-term endothelialization status of the occluder surface after LAAC.

Currently, there is no gold standard for the evaluation of occluder endothelialization after LAAC. In this study, only 3D-TEE was used for evaluation of endothelialization, and the evaluation time was set according to previous animal studies. However, there is no relevant literature discussing the difference in endothelialization time of occluder between human and animal, which still requires further study.

\section{Conclusion}

In this study, we found that 3D-TEE played an important role in preoperative evaluation and postoperative monitoring of transcatheter LAAC. The measurements by 3D-TEE were well correlated with those by intraoperative angiocardiograph. After the operation, the cardiac function of AF patients gradually improved. Persistent AF, SEC of LAA blood flow or recent thrombotic event, and the history of embolism in other parts were influence factors of the endothelialization of occluder.

\section{Abbreviations}

AF: atrial fibrillation; HHT: hereditary hemorrhagic telangiectasia ; LAA: left atrial appendage; LAAC: left atrial appendage closure; LSPV: left superior pulmonary vein; NVAF: non-valvular atrial fibrillation; RT-3DTEE: real-time transesophageal three-dimensional echocardiography ; SEC: spontaneous echo contrast ; TTE: transthoracic echocardiography; 2D-TEE: transesophageal two-dimensional echocardiography; 3DTEE: transesophageal three-dimensional echocardiography

\section{Declarations}

\section{Ethics approval and consent to participate}

This report was approved by the Ethics Committee of Yantai Yuhuangding Hospital. Written informed consent was obtained from all the patients. 


\section{Consent for publication}

Not applicable.

\section{Availability of data and materials}

The datasets used and analysed during the current study are available from the corresponding author on reasonable request.

\section{Competing interests}

The authors declare that they have no competing interests.

\section{Funding}

No external funding declared.

\section{Authors' contributions}

LIHONG WANG (first author) and LEI SHI (co-first author) are responsible for designing of this article, drafting/revising the manuscript, control and guarantee that all aspects of the work were investigated and resolved. HONGYUE MAO (co-first author) and HONGYAN LI (co-first author) participated in collecting material and drafting the manuscript. GUIFANG SONG (corresponding author) are responsible for designing of this article and revising the manuscript. All authors read and approved the final manuscript.

\section{Acknowledgements}

This study was supported by the Yantai Science and Technology Project of China (grant No. 2017YD010).

\section{References}

[1] Li Y, Wu YF, Chen KP, Li X, Zhang X, Xie GQ, Wang FZ, Zhang S. Prevalence of atrial fibrillation in China and its risk factors. Biomed Environ Sci 2013; 26:709-716.

[2] Beinart R, Heist EK, Newell JB, Holmvang G, Ruskin JN, Mansour M. Left atrial appendage dimensions predict the risk of stroke/TIA in patients with atrial fibrillation. J Cardiovasc Electrophysiol 2011; 22:1015.

[3] Chiang CE, Okumura K, Zhang S, Chao TF, Siu CW, Wei Lim T, Saxena A, Takahashi Y, Siong Teo W. 2017 consensus of the Asia Pacific Heart Rhythm Society on stroke prevention in atrial fibrillation. J Arrhythm 2017; 33:345-367.

[4] Camm AJ, Kirchhof P, Lip GY, Schotten U, Savelieva I, Ernst S, Van Gelder IC, Al-Attar N, Hindricks G, Prendergast B, et al. Guidelines for the management of atrial fibrillation: the Task Force for the 
Management of Atrial Fibrillation of the European Society of Cardiology (ESC). Eur Heart J 2010; 31: 2369-2429.

[5] Chang SS, Dong JZ, Ma CS, Du X, Wu JH, Tang RB, Xia SJ, Guo XY, Yu RH, Long DY, et al. Current Status and Time Trends of Oral Anticoagulation Use Among Chinese Patients With Nonvalvular Atrial Fibrillation: The Chinese Atrial Fibrillation Registry Study. Stroke 2016; 47:1803-1810.

[6] Wang ZZ, Du X, Wang W, Tang RB, Luo JG, Li C, Chang SS, Liu XH, Sang CH, Yu RH, Long DY, Wu JH, Bai R, Liu N, Ruan YF, Dong JZ, Ma CS. Long-Term Persistence of Newly Initiated Warfarin Therapy in Chinese Patients With Nonvalvular Atrial Fibrillation. Circ Cardiovasc Qual Outcomes 2016; 9:380-387.

[7] Kirchhof P, Benussi S, Kotecha D, Ahlsson A, Atar D, Casadei B, Castella M, Diener HC, Heidbuchel H, et al. 2016 ESC Guidelines for the management of atrial fibrillation developed in collaboration with EACTS. Europace 2016; 18:1609-1678.

[8] January CT, Wann LS, Calkins H, Chen LY, Cigarroa JE, Cleveland JC, Jr., Ellinor PT, Ezekowitz MD, Field ME, et al. 2019 AHA/ACC/HRS Focused Update of the 2014 AHA/ACC/HRS Guideline for the Management of Patients With Atrial Fibrillation: A Report of the American College of Cardiology/American Heart Association Task Force on Clinical Practice Guidelines and the Heart Rhythm Society in Collaboration With the Society of Thoracic Surgeons. Circulation 2019; 140:e125-e151.

[9] Holmes DR, Jr., Kar S, Price MJ, Whisenant B, Sievert H, Doshi SK, Huber K, Reddy VY. Prospective randomized evaluation of the Watchman Left Atrial Appendage Closure device in patients with atrial fibrillation versus long-term warfarin therapy: the PREVAIL trial. J Am Coll Cardiol 2014; 64:1-12.

[10] Reddy VY, Holmes D, Doshi SK, Neuzil P, Kar S. Safety of percutaneous left atrial appendage closure: results from the Watchman Left Atrial Appendage System for Embolic Protection in Patients with AF (PROTECT AF) clinical trial and the Continued Access Registry. Circulation 2011; 123:417-424.

[11] Reddy VY, Doshi SK, Kar S, Gibson DN, Price MJ, Huber K, Horton RP, Buchbinder M, Neuzil P, Gordon NT, Holmes DR, Jr., Prevail, Investigators PA. 5-Year Outcomes After Left Atrial Appendage Closure: From the PREVAIL and PROTECT AF Trials. JJ Am Coll Cardiol 2017; 70:2964-2975.

[12] Saw J, Lempereur M. Percutaneous left atrial appendage closure: procedural techniques and outcomes. JACC Cardiovasc Interv 2014; 7:1205-1220.

[13] January CT, Wann LS, Alpert JS, Calkins H, Cigarroa JE, Cleveland JC, Jr., Conti JB, Ellinor PT, Ezekowitz MD, et al. 2014 AHA/ACC/HRS guideline for the management of patients with atrial fibrillation: a report of the American College of Cardiology/American Heart Association Task Force on Practice Guidelines and the Heart Rhythm Society. J Am Coll Cardiol 2014; 64:e1-76.

[14] Müller S, Feuchtner G, Bonatti J, Muller L, Laufer G, Hiemetzberger R, Pachinger O, Barbieri V, Bartel T. Value of transesophageal 3D echocardiography as an adjunct to conventional 2D imaging in 
preoperative evaluation of cardiac masses. Echocardiography 2008; 25:624-631.

[15] Asch FM, Bieganski SP, Panza JA, Weissman NJ. Real-time 3-dimensional echocardiography evaluation of intracardiac masses. Echocardiography 2006; 23:218-24.

[16] Zhou Q, Song H, Zhang L, Deng Q, Chen J, Hu B, Wang Y, Guo R. Roles of real-time three-dimensional transesophageal echocardiography in peri-operation of transcatheter left atrial appendage closure. Medicine (Baltimore) 2017; 96:e5637.

[17] Ausma J, Wijfells MC, van EYSG, Koide M, Ramaekers F, Allessie M, Borgers M. Differentiation of atrial cardiomyocytes as a result of chronic atrial fibrillation. Am J Pathol 1997; 151:985-997.

[18] Frustaci A, Chimenti C, Bellocci F, Morgante E, Russo MA, Maseri A. Histological substrate ofatrial biopsies in patients with lone atrial fibrillation. Circulation 1997; 96:1180-1184.

[19] Meng QG, Zeng J, Lu C, Zhang QF, Wang Y, Lin N, Deng Y, Yin LX. Evaluation of short-term left atrial function after percutaneous atrial appendage closure by echocardiography. J Ultras Clin Med 2019; 21:94-97.

[20] Lammers J, Elenbaas T, Meijer A. Thrombus formation on an Amplatzer closure device after left atrial appendage closure. Eur Heart J 2013; 34:741.

[21] Massarenti L, Yilmaz A. Incomplete endothelialization of left atrial appendage occlusion device 10 months after implantation. J Cardiovasc Electrophysiol 2012; 23:1384-1385.

[22] Schwartz RS, Holmes DR, Van Tassel RA, Hauser R, Henry TD, Mooney M, Matthews R, Doshi S, Jones RM, Virmani R. Left atrial appendage obliteration: mechanisms of healing and intracardiac integration. JACC Cardiovasc Interv 2010; 3:870-877.

[23] Lock JE, Rome JJ, Davis R, Van Praagh S, Perry SB, Van Praagh R, Keane JF. Transcatheter closure of atrial septal defects. Experimental studies. Circulation 1989; 79:1091-1099.

[24] Granier M, Laugaudin G, Massin F, Cade S, Winum PF, Freitag C, Pasquie JL. Occurrence of Incomplete Endothelialization Causing Residual Permeability After Left Atrial Appendage Closure. J Invasive Cardiol 2018; 30:245-250.

[25] Watson T, Shantsila E, Lip GY. Mechanisms of thrombogenesis in atrial fibrillation: Virchow's triad revisited. Lancet 2009; 373:155-166.

[26] Scridon A, Girerd N, Rugeri L, Nonin-Babary E, Chevalier P. Progressive endothelial damage revealed by multilevel von Willebrand factor plasma concentrations in atrial fibrillation patients. Europace 2013; 15:1562-1566. 
[27] Prosperi-Porta G, Schnell G, Colbert J, Franko A, Wilton SB, Kuriachan VP. Multiple Thromboembolic Events from a Left Atrial Appendage Occlusion Device. Can J Cardiol 2018; 34:342 e13-42 e15.

\section{Tables}

Table 1. Comparison of parameters measured before operation, 3 months after and 6 months after left atrial appendage closure.

\begin{tabular}{llllll}
\hline & Before operation & 3 months post operation & 6 months post operation & F & $P$ \\
\hline LAD & $42.37 \pm 6.09$ & $42.00 \pm 6.15$ & $38.72 \pm 6.63$ & 28.49 & $<0.001^{*}$ \\
LVD & $47.10 \pm 5.66$ & $47.07 \pm 5.48$ & & 22.89 & $<0.001^{*}$ \\
MV E & $0.95 \pm 0.24$ & $0.96 \pm 0.29$ & $43.19 \pm 6.51$ & 0.09 & 0.92 \\
EDV & $149.70 \pm 52.23$ & $152.30 \pm 65.71$ & $0.94 \pm 0.30$ & 0.05 & 0.95 \\
SV & $90.30 \pm 25.47$ & $91.30 \pm 24.75$ & $148.30 \pm 54.32$ & 0.06 & 0.94 \\
FS & $33.25 \pm 1.64$ & $34.15 \pm 1.43$ & $93.15 \pm 28.97$ & 1.07 & 0.36 \\
CO & $8.12 \pm 3.31$ & $7.35 \pm 2.30$ & $34.85 \pm 1.22$ & & \\
EF & $60.85 \pm 10.86$ & $62.15 \pm 8.91$ & $6.98 \pm 2.33$ & 1.49 & 0.27 \\
E/E' & $11.55 \pm 3.85$ & $8.47 \pm 2.99$ & $63.45 \pm 7.90$ & 1.60 & 0.23 \\
\hline
\end{tabular}

LAD: left atrial diameter; LVD: left ventricular diameter; MV E: peak velocity of mitral valve; EDV: end diastolic volume of left ventricle; SV: stroke volume; FS: fractional shortening of left ventricle; CO: cardiac output; EF: ejection fraction; E/E': peak velocity of mitral valve-to-distance of left ventricular free wall mitral annulus movement ratio; * : statistical significance.

Table 2. Comparison of clinicopathological parameters between left atrial appendage spontaneous echo contrast (SEC) group and non-SEC group. 


\begin{tabular}{llll}
\hline & SEC group & Non-SEC group & $P$ \\
\hline Age (yrs) & $65.46 \pm 8.70$ & $46.46 \pm 9.56$ & 0.65 \\
Gender (Male) & $24(77.42 \%)$ & $24(64.86 \%)$ & 0.05 \\
Smoking & $13(41.94 \%)$ & $13(35.14 \%)$ & 0.56 \\
Hypertension & $21(67.74 \%)$ & $18(48.65 \%)$ & 0.26 \\
Stroke & $18(58.06 \%)$ & $26(70.27 \%)$ & 0.27 \\
Persistent atrial fibrillation & $29(93.55 \%)$ & $25(67.57 \%)$ & $0.02^{*}$ \\
CHA $_{2}$ DS & & & \\
BNP (pgscScore & $3(3,5)$ & $4(3,5)$ & 0.16 \\
\hline
\end{tabular}

*: statistical significance.

Table 3. Influence factors of endothelialization of occluder surface after left atrial appendage closure. 


\begin{tabular}{|c|c|c|c|c|c|}
\hline \multirow[b]{2}{*}{ Variables } & \multicolumn{2}{|c|}{ Unstandardized Coefficient } & \multirow{2}{*}{$\begin{array}{l}\text { Standardized Coefficient } \\
\beta\end{array}$} & \multirow[b]{2}{*}{$\mathrm{t}$} & \multirow[b]{2}{*}{ Sig. } \\
\hline & $\mathrm{B}$ & $\mathrm{SE}$ & & & \\
\hline Age & 0.00 & 0.00 & 0.45 & 0.70 & 0.33 \\
\hline Gender & 0.03 & 0.03 & 0.43 & 0.77 & 0.48 \\
\hline Smoking & 0.01 & 0.03 & 0.23 & 0.36 & 0.73 \\
\hline Hypertension & -0.02 & 0.02 & -0.03 & -0.09 & 0.93 \\
\hline Persistent atrial fibrillation & -0.01 & 0.03 & -0.24 & -0.38 & $0.02^{*}$ \\
\hline $\mathrm{CHA}_{2} \mathrm{DS}_{2}$-VASc score & 0.01 & 0.02 & 0.79 & 0.70 & 0.51 \\
\hline HAS-BLEDS score & 0.02 & 0.01 & 0.56 & 1.33 & 0.24 \\
\hline Combined intraoperative radiofrequency ablation & 0.00 & 0.0 & 0.07 & 0.13 & 0.90 \\
\hline LAA velocity & 0.00 & 0.00 & -0.27 & -0.50 & 0.64 \\
\hline LAA classification & 0.04 & 0.02 & 0.74 & 1.87 & 0.12 \\
\hline LAA otrium maximum diameter & 0.00 & 0.00 & 0.09 & 0.16 & 0.88 \\
\hline LAA maximum depth & -0.02 & 0.00 & -0.44 & -0.69 & 0.52 \\
\hline SEC or recent thrombotic event & -0.04 & 0.03 & -0.77 & -1.40 & $0.01^{*}$ \\
\hline History of embolism & -0.04 & 0.03 & -0.72 & -1.59 & $0.03^{*}$ \\
\hline
\end{tabular}

SE: standard error; LAA: left atrial appendage; SEC: spontaneous echo contrast; ${ }^{*}$ : Statistical significance.

\section{Figures}




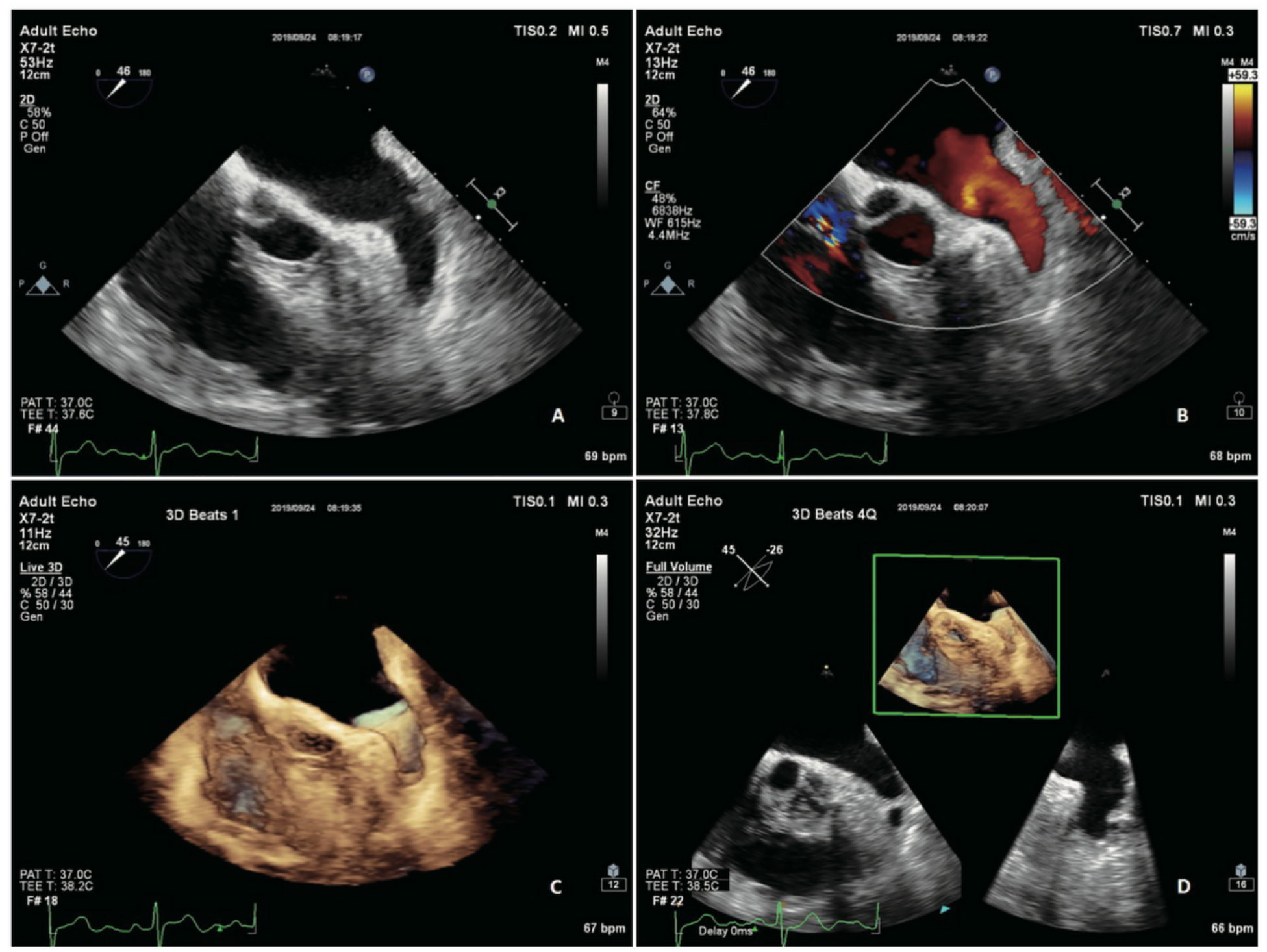

\section{Figure 1}

Preoperative transesophageal echocardiography evaluation of left atrial appendage. (A) Twodimensional transesophageal echocardiography evaluation. (B) Color Doppler flow imaging of left atrial appendage. (C) Three-dimensional Transesophageal echocardiography (3D-TEE) evaluation. (D) Multisection real-time 3D-TEE evaluation. 


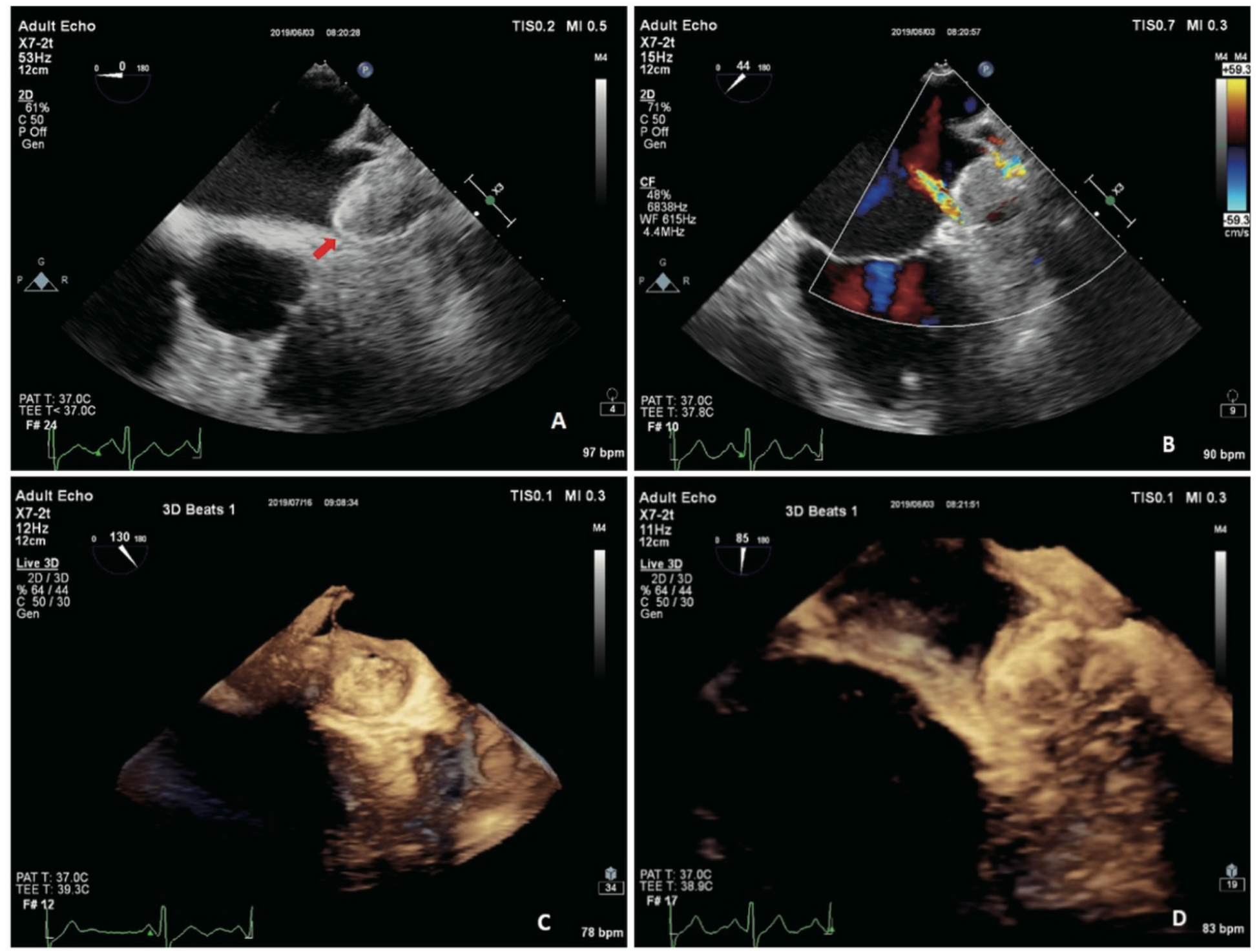

\section{Figure 2}

Intraoperative evaluation after occluder implantation. (A) Evaluation of the position, shape, shoulder protrusion and compression ratio of occluder by two-dimensional transesophageal echocardiography. (B) Evaluation of residual flow by Color Doppler ultrasonography. (C, D) Evaluation of the occluder by threedimensional Transesophageal echocardiography. 


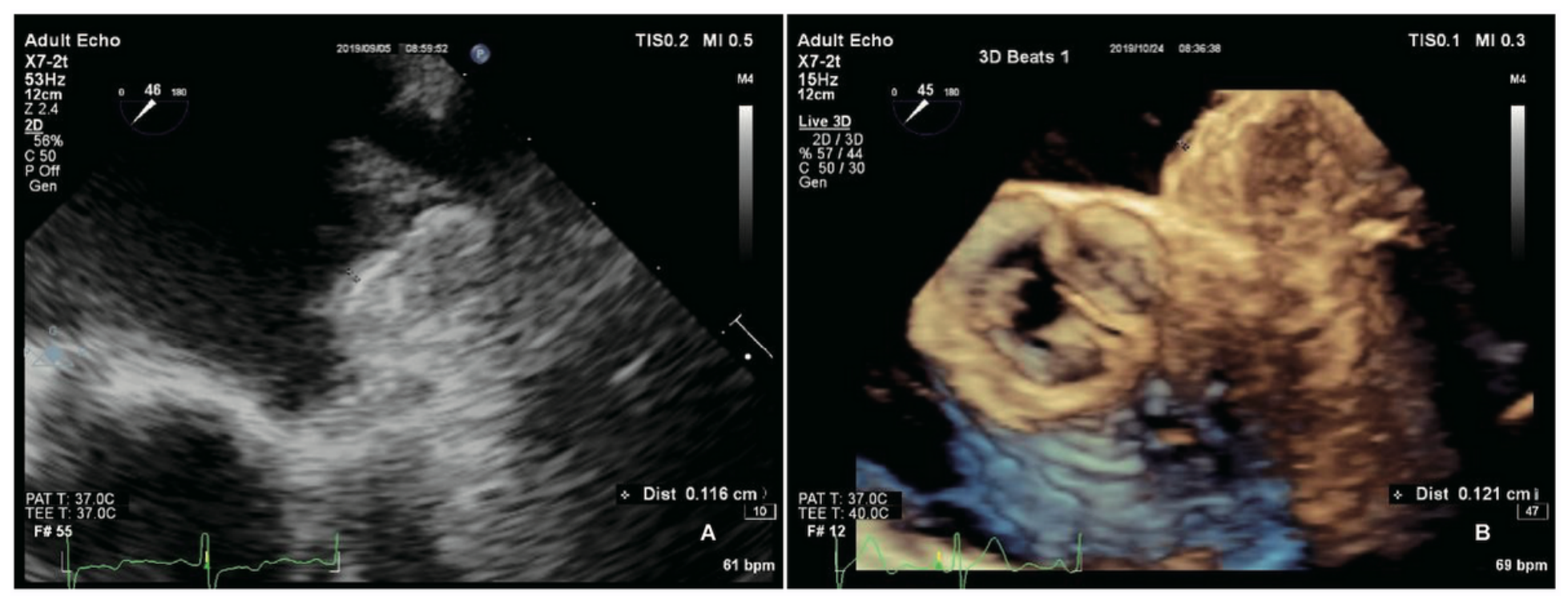

Figure 3

Measurement of the thickness of endothelialization of the occluder surface by (A) 2D-TEE and (B) 3DTEE. 

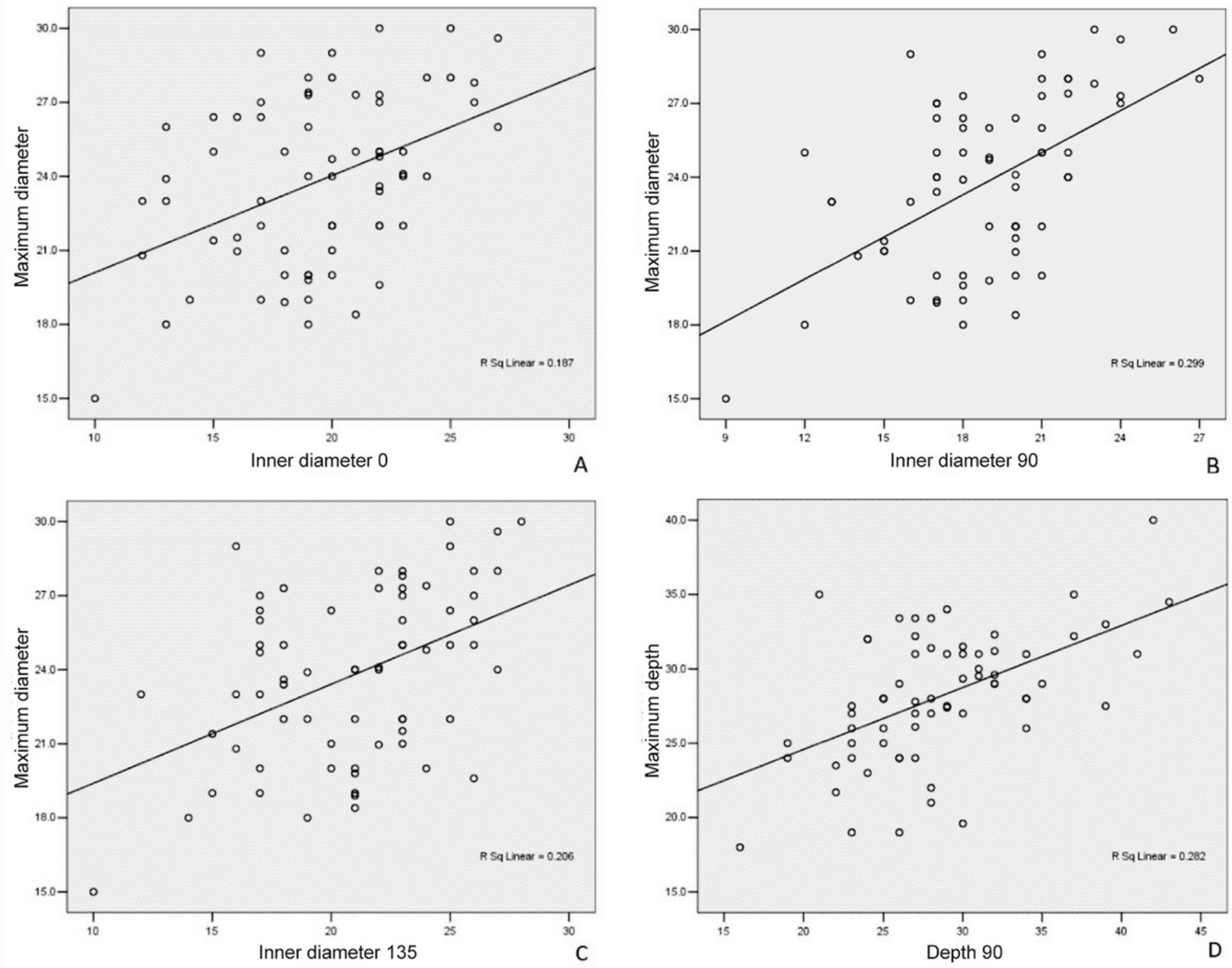

\section{Figure 4}

Correlation between measurements by transesophageal echocardiography (TEE) and intraoperative angiocardiography. Correlation between the inner diameter measured by TEE at (A) $0^{\circ}$, (B) $90^{\circ}$, and (C) $135^{\circ}$ and the maximum diameter measured by angiocardiography. (D) Correlation between the depth measured by TEE at $90^{\circ}$ and the maximum depth measured by angiocardiography. 